\title{
INTERPRETATION OF COAL POTENTION USING GROUND PENETRATING RADAR (GPR) METHOD
}

\author{
Rohmatul Wahidah*, Abdul Basid \\ Department of Physics, Science and Technology Faculty \\ Universitas Islam Negeri Maulana Malik Ibrahim Malang \\ Gajayana No. 50 Malang 65144
}

\begin{abstract}
Coal exposure founded at Klatak Kebo Ireng village in Besuki Tulungagung precisely in the vicinity of the river. Energy needs are increasing so the coal used for an alternative energy source that can be used by society. This study was conducted to determine the potential distribution coal modeling on the geological structure. Identification of coal structure used Ground Penetrating Radar (GPR) 2005 which is more suitable for shallow of surveys. The location for taking data is around the river. There are five lines of taken data with length about 50 to 100 meters. Data processing was done using of software Future series 2005. The data displayed with software in the color pattern to obtain based on the constant of dielectric and conductivity. The results of interpretation study are the data indicates that there is coal on the overall trajectory. Only in $2^{\text {nd }}$ track contain little of coal. The Coal layers appear in processing the results of data is thickness about six at the top. In the area of study also found the cavity (cavity area) which contained several tracks. On the bottom of the track, there is a pattern of coal reddish of yellow color which indicates the presence of minerals.
\end{abstract}

Keywords: Coal; Electromagnetic Waves; Ground Penetrating Radar (GPR)

\section{Introduction}

The one of an alternative energy source that it's existence potention is enough abundant in our country is coal. In Java island, Kebo Ireng village in Besuki Tulungagung there is coal exposure in the edge of the river.

According to geology the research location is on Mandalika Formation that consist of breccia volcano is brownish ashen chromatic until ashen greenness, cohesive, massive; consisting of component andesite, dacite, diorite and basalt. ${ }^{1}$

The purpose of this research is to estimate foots up coal for exploration. Ground Penetrating Radar (GPR) Method is one of the methods for Coal identification in which the character, structure, etc. can be studied

Coal is the sedimentary rock that can firing, formed of rest plant that most humification. Its color is dark brown until black. The carbon content increases due to physical processes and chemical occured in millions of years. ${ }^{2}$ Based on formation proccess step that controlled by pressure, heat and time, coal agglomerates in five classes: antracite, bituminous, subbituminous, lignit and peat. ${ }^{3}$

The begining process of coal formation is planted settle changed to be peat, the change to be lignit as know as brown coal. After getting influence by temperature and pressure perpetually up to millions of years, so lignit will experience changing that step by step adds organic maturity and alterations lignite as sub-bituminous coal. The change by chemical and physical perpetually continue until coal change is harder, and the colour goes darker and changes to be bituminous or anthracite. In condition in point, the creasing of maturity organic that excelsior goes on until anthracite form. ${ }^{4}$

Wave is the one of thing that is base on this research. Radar work system is with

\footnotetext{
* Corresponding Author

Email: rohmaw62@gmail.com
} 
radiatte micro wave perpetually to all aim by the transmitter. If there is an object that hit the wave, the signal will be reflected by the object and will be accepted by the receiver. The reflected signal will give information of the presence object that there in the under surface soil that will feature on display. ${ }^{5}$

GPR is the one of a geophysic method to learning sub-terranean condition base of electromagnetic character that has frequency value range $1-1000 \mathrm{MHz}$ and can detect parameter electric permitivity $(\varepsilon)$, conductivity $(\sigma)$ dan magnetic permeability $(\mu){ }^{6}$

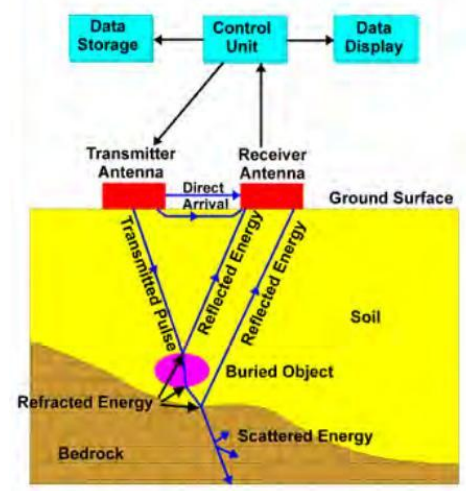

Figure 1. Work system of GPR

Work system of GPR on figure 1 comprises trasmitter, an antenna connected to the pulse source, receiver, an antenna connected to the signal processing unit and image. ${ }^{7}$ The general principle of GPR is transmitting radar wave (radio detection and ranging) to the target medium. Furthermore, these radar waves reflected to surface soil and accepted by radar receiver tool. It eventually generated a various object which detected and recorded a radar gram. By the above process, it produced an image position and object form on surface soil or in subterranean. ${ }^{8}$

If the soil is homogen so the reflected signal will be small. If the signal collides an inhomogenity in sub-terranean, there are the reflected signals hit the receiver antenna. Then this signal is processed by receiver series. The object depth can be measured using a time gap between emission and pulse acceptance. $^{8}$
To detecting the object needed the difference parameter electric of medium that is passed by radar wave. The difference parameter electric for example electric permitivity, conductivity and magnetic permeability. Electromagnetic character of the materal is dependent on composition and water content in it, whereabouts both constituting main influence on speed of wave radar and attenuation electromagnetic wave in significant. ${ }^{8}$

\section{Methods}

The taking data of this research is on 2223 Mei 2017. The location of this study is in the region of coal exposure at Klatak Kebo Ireng village in Besuki Tulungagung.

It used GPR (Ground Penetrating Radar) Future Series 2005 by using the electromagnetic character as travel time of radio wave that has frequency range 25-1000 MHz. GPR'S tool (Ground Penetrating is Radar) Future series 2005 this consisting of the subject unit which is:

1. Censor hilt

2. Power supply is unit

3. Control is unit

4. Connecting cable

5. Censor

6. Gauge

7. Notebook PC

8. Bluetooth

9. Software

The procedure this observational perform consisted of 3 phases, i.e., data pra acquisition phases, data acquisition phases, and data pasca acquisition phases. Data pra acquisition phases include the literature study, litology information, and survey location. Data acquisition phases are consist of taking data that done in location research. The retrieval techniques in consist of some steps, which are:

1. Determining trajectory, total trajectory who will do taking.

2. Arranging tool Ground Penetrating is Radar (GPR) accord procedure.

3. Start-up power supply.

4. Determining impulse on Ground Penetrating is Radar (GPR). 
5. Linking tool Ground Penetrating is Radar (GPR) with the notebook is PC utilize bluetooth.

6. Pressing switch ready on Ground Penetrating is Radar (GPR).

7. Doing taking data by carries on censor Ground Penetrating is Radar (GPR) upon the surface soil.

8. Going over steps upon on succeeding trajectory.

Then the data acquisition will continue on processing data. The processing data conducted by using visualizer 3D software that constitutes one package with Ground Penetrating Radar (GPR) Future series 2005 that will feature straight forward taking data results. Data pasca acquisition phases are consist of analysis or interpretation data. Research data is a data scan 2D that processed using Visualizer 3D software, so it can interprete its bases electromagnetic wave spectrum on the figures spread coal in the observational region.

\section{Result and Discussion}

Data analysis from Ground Penetrating Radar (GPR) method is conducted to determine the coal layer and mapping the cola scatters. The data collected is displayed by picture soil layer with a different colour in each of layer. The data obtained by differences in dielectrics contansta and conductivity of each layer.

The determinant factor of GPR method is a constanta dielectric of soil and a dimension of an object related to the depth. Particular cases are the wet soil, clay, and sand which has high conductivity.

On GPR Future Series 2005 legend from above to bottom (blue color to red color) show that the conductivity value is increasing and the resistivity decreasing. Meanwhile, from base to high spektrum (red color to blue color), the conductivity value is decreasing.

The blue color that constitutes cavity area has low conductivity. Meanwhile, green color that is a high blue color has superordinate conductivity than blue color conductivity. The red color that points out to mark sense metal has the highest conductivity.

The blue color in Figure 2 shows the existence of a cavity area. Furthermore, the dark green color indicates that the area is a wet area. The yellow color indicates a dry area whereas the reddish yellow color shows the existence of minerals. The red color forms a specific pattern for a metal presence.

Data retrieval in this study used five trajectories. The research area is a watershed area and on the banks of the river is a coal outcrop.

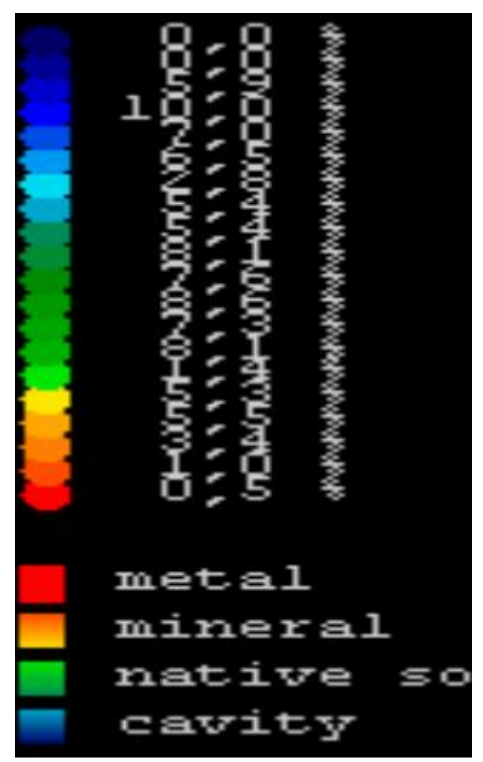

Figure 2. Object Types Classified by Color Variations 


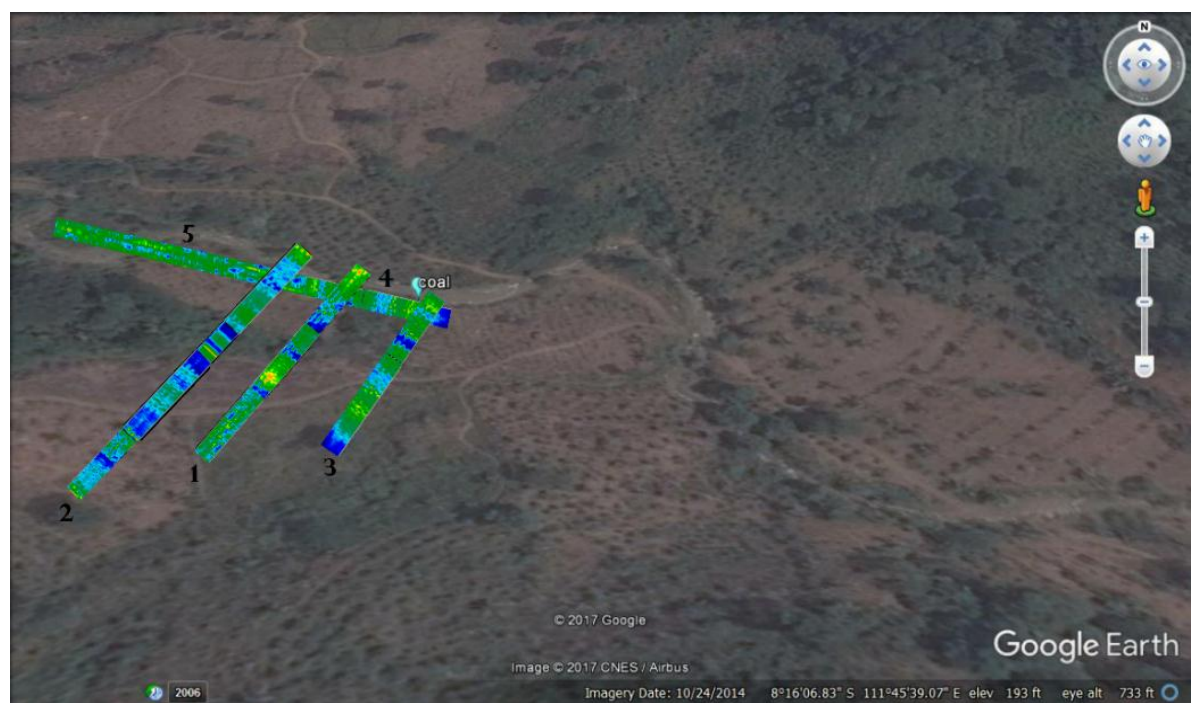

Figure 3. Data Research on Google Earth

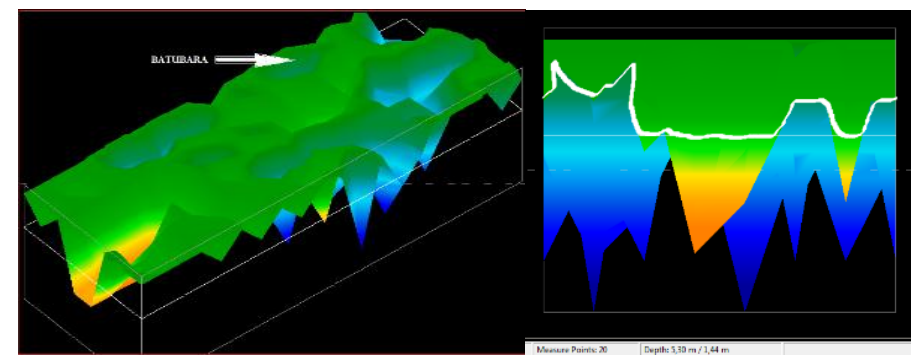

Figure 4. 3D Cross Section and Vertical Data Sample
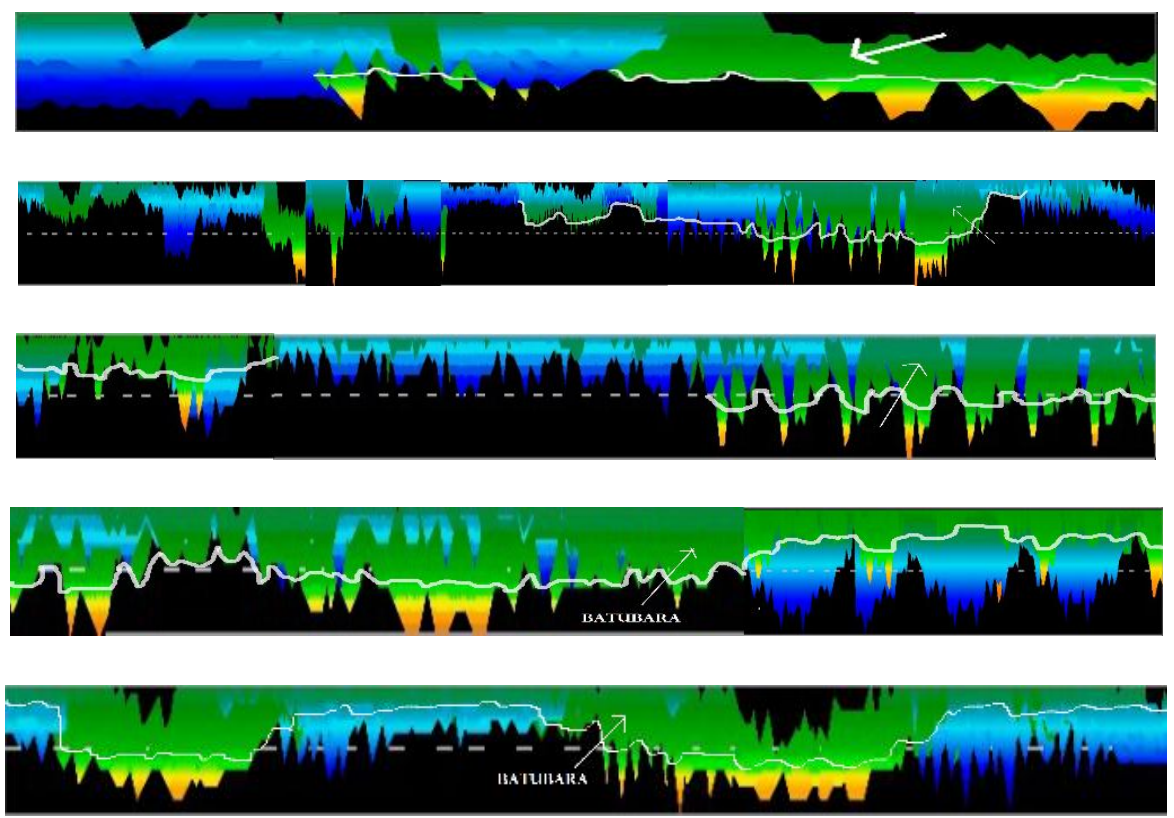

Figure 5. Vertical Cross Section Track 1 Until Track 5

The five trajectories appear in Fig. 3 where the entire tracks present an intersection between one track and another track. Data collection performed on the outcrop of coal on the banks of the river. The results of the scan on the sample data in Figure 4 indicate the presence of coal shown by the green color.

Figure 5 shows the vertical cross section of the research data. In track 1 indicates a continuous green layer pattern from beginning to the end of track. It shows the 
presence of coal layer in the area and the depth along track 1 is relatively same with the depth 6 meters. The green color pattern on track 2 appears in the middle layer. Meanwhile, On the top layer covered by a blue color pattern which denotes a cavity area. On tracks 3 and 4 indicate the presence of a thick layer of coal, especially in the middle of the coal layer. The measurable depth of coal layer on track 3 and track 4 is 5,7 meters and 5 meters, respectively. Trajectory 5 dominated by a green color pattern indicating a coal layer with a depth of 5,6 meters. The result scans show the presence of coal seams found throughout the track.

\section{Conclusions}

Based on the results of data retrieval, processing and interpretation conducted using Ground Penetrating Radar (GPR) method Future Series 2005, it concludes that a qualitative interpretation of 3D visualization presents a layer of coal beneath the surface with a thickness of about 5 meters. Potential coal mapping offers the entire data in which Coal potentials appear on tracks 1, 3, 4 and 5. Furtheremore, on track 2, coal seems are visible only at some point.

\section{Acknowledgments}

Thank for the Head of Geophysics Laboratory Science Faculty, Brawijaya University and the Head of Center Laboratory Science Faculty, Malang State University for the supports.

\section{References}

1. Samodra, H., Suharsono, S. Gafoer dan T. Suwarti. Geology of Lembar Tulungagung, Java. Bandung: Center For Geological Research and Development; 1992.

2. Anggayana, Komang. Genesa Coal. Bandung: Departement of Mining Engineering Institite of Technology Bandung; 2002. [In Indonesia]

3. Sutarno. Energy Resources. Yogyakarta; Graha Ilmu; 2013. [In Indonesia]
4. Iswati, Y. Core and Lost Deflection Analysis Los in Determining The Environment of Precipitation and Coal Deposite at Banko Barat Pit 1, South Sumatera [Essay]. Bandar Lampung: Department of Geophysics Engineering University of Lampung; 2012 [accessed on 20 Maret 2017]; digilib.unila.ac.id/scr_yuni_0715051041

5. Muhyi, Sumarsono. Underground Electrical Cable Detection with Otomata. Jakarta: STMIK Indonesia; 2012.

6. Annan, A.P. dan Davis J.L. Ground Penetration Radar for High Resolution Mapping of Soil and Rock Statigraphy. Canada: Geophys Prospect; 1989.

7. Bahri, Ayi Saiful. Characteristic Determination of Seropan Gunungkidul Cave with Ground Penetrating Radar Method [thesis]. Surabaya: Sepuluh Nopember Institute of Technology; 2009 [accessed on 3 Maret 2017]; digilib.its.ac.id/public/ITS-undergraduate -12481-paper.pdf

8. Hakim, Agung Mahesya, Alwi Karya S., Asri Wulandari, Bagus H. dan C. Sibuea. Electromagnetic Exploration Module. Bandar Lampung; Department of Geophysics Engineering University of Lampung. 2011.

9. Shofiana, Anggun. Identification of Underground Caverns on Limestone Structures Based on Interpretation of Ground Penetrating Radar Data. Malang: State Islamic University of Maulana Malik Ibrahim. 2016.

10. Yulius, Yudi M. Database Processing and Visualization Study Ground Penetrating Radar. Jakarta: Journal of Electronic and Telecommunication Research Center LIPI. 2014.

11. Ubaidillah, Anwar Prabu. Study of Georadar Tools OKO-2 Frequency 250 $\mathrm{MHz}$ and $400 \mathrm{MHz}$ For Geometry Characteristics, Cleat Orientation And Water Content On Coal Layer. Palembang: Sriwijaya University. 2011. 